\title{
Tertulias dialógicas literarias como actuación educativa de éxito para mejorar la competencia lingüística.
}

Dialogical literary circles as a successful educational action to improve linguistic competence.

Ascensión Palomares Ruíz

Facultad de Educacion de Albacete. Universidad de Castilla-La Mancha (España)

Ascension.Palomares@uclm.es

Francisco Javier Domínguez Rodríguez

Facultad de Educación de Ciudad Real. Universidad de Castilla-La Mancha (España)

Francisco.Dominguez@uclm.es

Fecha recepción: 17/07/2019

Páginas 38-53

Fecha aceptación: 25/11/2019

\section{Resumen.}

Este artículo muestra una investigación en la que, mediante distintas actuaciones educativas de éxito, se visualiza el aprendizaje dialógico. Entre ellas, se encuentran las tertulias dialógicas literarias, donde el diálogo igualitario se convierte en un esfuerzo común para lograr la equidad educativa, favoreciendo el desarrollo de la competencia en comunicación lingüística. Se realiza un estudio de un caso, con una metodología que responde al enfoque comunicativo crítico, describiendo e interpretando la realidad, y pretende su transformación. El análisis de la información recogida a través de las técnicas de grupos de discusión comunicativos y el relato comunicativo de vida cotidiana, se ha realizado de manera cualitativa. Además, se analizan de manera cuantitativa los resultados obtenidos en un colegio de Linares (Jaén). Se evidencia que, las interacciones en las tertulias dialógicas literarias promueven el desarrollo de la comunicación oral y escrita, fomentan la interpretación, comprensión y reflexión crítica de la realidad.

Palabras clave: competencia lingüística; aprendizaje dialógico; comunidades de aprendizaje; tertulias dialógicas; inclusión educativa

\begin{abstract}
.
This article shows a commitment to learning dialogue by the implementation of educative actions for success that this project supports, where the equal dialogue turns into a shared effort to achieve educational equality, they will favor the development of the competence in linguistic communication. A case study is carried out, with a methodology that responds to critical communicative approach, describing and interpreting reality, and intends its transformation. The analysis of the information collected through the techniques of communicative discussion groups and the communicative story of daily life, it has been done qualitatively. Further, the results
\end{abstract}


obtained are analyzed quantitatively in a school of Linares (Jaén). It is evident that, Interactions in literary dialogical gatherings promote the development of oral and written expression, encourage interpretation, understanding and critical reflection of reality.

Keywords: linguistic competence; dialogical learning; learning communities; dialogical circles; educational inclusion

\section{1.-Introducción.}

Los conceptos de Educación Inclusiva (Ainscow, Farrell, \& Tweddle, 2000; Dyson, 2001; Echeita, 2008, Escudero \& Martínez, 2011) y Comunidades de Aprendizaje (School Development Program (Programa de Desarrollo Escolar) de la Yale University (Comer, 1996, 1999), Success for All (Éxito para Todos), de la Johns Hopkins University (Slavin, 1996a, 1996b, 1998) y Accelerated Schools (Escuelas Aceleradas), de la Stanford University (Levin, 1987, 1993, 1995), a pesar de que sus antecedentes teóricos procedan de diferentes líneas de investigación, están destinados a confluir. Efectivamente, inclusión, comunidad, colaboración, participación, diálogo y compromiso, son conceptos muy relacionados que es preciso abordar conjuntamente en orden a combatir la exclusión, la segregación, el desapego, las barreras para el aprendizaje, el abandono y el fracaso escolar, y conseguir escuelas resistidas sobre ideales de justicia social, democracia y equidad, donde el alumnado adquiera una educación de calidad como condición mínima indispensable para gozar de una vida digna (González \& Escudero, 2017).

Comunidades de Aprendizaje es un proyecto basado en un conjunto de actuaciones educativas de éxito dirigidas a la transformación social y educativa. En este sentido, Elboj, Puigdellívol, Soler y Valls (2002), especifican:

"En las Comunidades de Aprendizaje todos los miembros implicados sueñan y construyen la escuela que quieren para sus hijos e hijas con el objetivo de mejorar su educación. La participación de todos y todas es lo que hace posible transformar esa realidad, por más inmutable que parezca, en base a unos principios como el diálogo, la igualdad y la solidaridad" (Elboj, Puigdellívol, Soler \& Valls, 2002, p.61).

En la misma línea, Valls (2005), puntualiza que:

"Una comunidad de aprendizaje es un proyecto de transformación social y cultural de un centro educativo y de su entorno para conseguir una Sociedad de la Información para todas las personas, basada en el aprendizaje dialógico, mediante una educación participativa de la comunidad, que se concreta en todos sus espacios, incluida el aula" (Valls 2005, p. 33).

Este modelo educativo está en consonancia con las teorías científicas a nivel internacional, entre las que destaca la Teoría del Aprendizaje Dialógico (Flecha, 1997; Aubert et al, 2008). Esta teoría parte de las contribuciones de algunos de los 
autores más relevantes en ciencias sociales y del aprendizaje (Vygotsky, 1979; Habermas, 1987; Freire, 1997). Todas ellas destacan dos factores claves para el aprendizaje: las interacciones y la implicación de toda la comunidad. Las Comunidades de Aprendizaje involucran a los individuos que, directa 0 indirectamente, influyen en el aprendizaje y el desarrollo de las personas, incluyendo a profesorado, familiares, amistades, miembros del barrio, asociaciones y organizaciones vecinales y locales, voluntariado, etc. (Valls \& Kyriakides, 2013).

El proyecto Comunidades de Aprendizaje empezó en la enseñanza obligatoria en 1995 y, en la actualidad, cuenta en España con más de trescientas Comunidades de Aprendizaje. Debido a su éxito, las Comunidades de Aprendizaje se han extendido a nivel internacional, llevándose a cabo en centros educativos de Sudamérica y se han apreciado, dentro del Sexto Programa Marco de Investigación de la Unión Europea INCLUD-ED, como una actuación de éxito para el fomento de la cohesión social en Europa a través de la educación (INCLUD-ED, 2011). Consecuentemente, fruto de su impacto, se han aprobado diversas resoluciones de la Comisión Europea y del Consejo de Europa que propician la organización de las escuelas como Comunidades de Aprendizaje para acabar con el abandono escolar en Europa y lograr así los objetivos planteados por la Estrategia Europa 2020 (MECD, 2013).

Las principales actuaciones educativas de éxito de las Comunidades de Aprendizaje son:

a) Los grupos interactivos.

b) Las tertulias dialógicas (literarias, musicales, artísticas...).

c) La formación de la familia.

d) La participación educativa de la comunidad.

e) El modelo dialógico de prevención y resolución de conflictos.

f) La formación dialógica del profesorado.

Partiendo de los sueños de toda la comunidad educativa y, a través del diálogo y la ciencia, este proyecto transformador está alcanzando un doble objetivo: superar el fracaso escolar y mejorar la convivencia. Estos objetivos se consiguen a través de las actuaciones educativas de éxito, todas ellas basadas en el "aprendizaje dialógico", convirtiéndose en el marco a partir del cual se llevan a cabo las actuaciones de superación en Comunidades de Aprendizaje. Desde esta perspectiva del aprendizaje, basada en una concepción comunicativa, se concibe que las personas aprenden a partir de las interacciones con otras personas. En este sentido, Flecha (2004), indica que:

"Las actuales sociedades multiculturales quedan expuestas a una encrucijada: reconstruyen nuevas formas de vivir juntos (Touraine) en base al diálogo y consenso entre una creciente pluralidad de voces o sufren las consecuencias del conflicto entre diferentes fundamentalismos. La salida a la encrucijada viene de la mano del diálogo y, donde éste se acaba, de su contrario: la violencia" (Flecha, 2004, p. 4).

Razonadamente, este artículo parte de una pregunta que pretende investigar el impacto de las tertulias dialógicas literarias como actuación educativa de éxito que se 
desarrolla en Comunidades de Aprendizaje, exponiendo los objetivos que se consiguen con dicha actuación y los resultados que se obtienen con su aplicación en el aula; es decir: ¿mejoran los resultados académicos y el desarrollo de la competencia en comunicación lingüística con la puesta en práctica en las aulas de las tertulias dialógicas literarias? Además, conviene subrayar que, dichos resultados no solamente se consiguen a través de llevar a cabo esta única actuación educativa de éxito, sino que también beneficia el llevar a cabo todas las actuaciones marcadas anteriormente junto a la participación de la comunidad educativa, bases del proyecto de comunidad de aprendizaje.

\section{2.-Marco teórico.}

\section{1.- Aproximación conceptual sobre las tertulias literarias dialógicas.}

Diversas investigaciones evidencian que las tertulias literarias dialógicas suponen una actuación educativa de éxito (Flecha, García \& Gómez, 2013; Torrego, Barba y Fernández, 2013; Foncillas \& Laorden, 2014). Naturalmente, el diálogo que se establece en las tertulias se aleja de la verticalidad, en la que el docente está en posesión de la verdad, estableciéndose un diálogo más crítico, reflexivo y enriquecedor, en el que se incluyen distintos puntos de vista, todos ellos válidos. Se trata de valorar las actitudes hacia la lectura, la implicación, la participación, la expresión oral, el respeto a los turnos de palabra, la adquisición de nuevo vocabulario, etc. Igualmente, como indica Freire (1970), este diálogo igualitario, se basa en la humildad, en la creencia y el respeto a los demás. En este sentido, Flecha et al. (2013) especifican que, los diálogos realizados en la tertulia van más allá del aula y se hacen presentes en distintos entornos, fundamentalmente los familiares implicándolos en su proceso de aprendizaje. Asimismo, las tertulias dialógicas mejoran el aprendizaje en los distintos contextos en los que se han desarrollado y contribuyen a la transformación de las personas participantes en ellas.

Las tertulias literarias dialógicas son reuniones de personas que se coordinan libremente para escoger una obra clásica que todas deben leer simultáneamente y suponen la aplicación de los principios del aprendizaje dialógico en relación con la literatura, música, matemáticas, historia, etc. Tienen como base las reflexiones, los debates y los argumentos, y las experiencias de vida cotidiana de las personas implicadas. Los participantes, se ponen de acuerdo en el número de páginas que deben leer $y$, posteriormente, se reúnen para comentar lo que han leído. Cada persona debe tener algún párrafo señalado o subrayado que le haya gustado especialmente, y explicará a los demás los motivos por los que ha elegido ese párrafo y no otro. Se aportan las reflexiones, dudas, núcleos de interés y debates que surgen a partir de dicha lectura. En estas tertulias puede participar voluntariamente cualquier miembro de la comunidad: alumnos, familia, profesorado, otras personas del barrio, voluntarios, etc. Así, se consigue que personas que no hayan leído nunca ningún libro lleguen a disfrutar de las obras de la literatura clásica universal (C.E.I.P. Padre Orbiso, 2003). No se pretende descubrir y analizar lo que el autor quiere decir en sus textos, sino fomentar el diálogo y la reflexión, a partir de las 
distintas interpretaciones que pueden surgir de un texto. Por ello, como indica Loza (2004), cualquier participante puede actuar como moderador, dando turnos de palabra, priorizando a las personas que menos participan en la tertulia, apreciando que no puede imponer su verdad, sino que debe favorecer que todos aporten sus argumentos para que puedan reflexionar y discutir hasta llegar al consenso.

Como indica Loza (2004), algunas de las finalidades que se pueden conseguir mediante estas tertulias podrían ser las siguientes:

a) Mejorar la competencia lectora, tanto en lectura silenciosa como en la oral.

b) Desarrollar la expresión oral.

c) Estimular y mejorar la comunicación escrita.

d) Dar sentido y funcionalidad a los aprendizajes relacionados con la comunicación oral en su doble vertiente de expresión y comprensión.

e) Conocer directamente obras y autores de la literatura clásica universal.

f) Realizar un análisis dialógico de obras y autores.

g) Reflexionar sobre diferentes metodologías relacionadas con la lectura.

h) Mejorar el diálogo entre todos los participantes.

i) Conseguir que se respeten los turnos de palabra.

j) Utilizar argumentos en la defensa de las opiniones.

k) Valorar críticamente las aportaciones de los participantes en las tertulianas.

I) Potenciar hábitos lectores.

m) Descubrir el lado lúdico de la lectura y de la literatura.

n) Generar una actitud de escucha en todos los participantes.

o) Desarrollar un espíritu crítico y solidario.

p) Aumentar la autoestima.

q) Analizar críticamente el universo de valores en los que estamos inmersos.

\section{2.- Desarrollo y funcionamiento de las tertulias dialógicas literarias.}

Las tertulias dialógicas literarias funcionan de una manera sencilla; sin embargo, para obtener los resultados propuestos, resulta preciso considerar varios aspectos, como:

a) Hay una persona que modera la sesión que puede cambiar en cada tertulia, y que explica brevemente las ideas principales del capítulo 0 fragmento que se va a trabajar.

b) Se selecciona un libro y se decide cuantos capítulos se leerán para la siguiente sesión.

c) Se abren turnos de intervenciones. Es necesario pedir palabra a la persona que modera, no interrumpir y no saltarse los turnos de palabra.

d) Es importante no excederse en las intervenciones, para fomentar la participación de más personas.

e) Se interviene haciendo referencia a párrafos concretos de la lectura.

f) Para intervenires necesario haberse leído la lectura que se ha establecido. Es necesario citar la página y el párrafo a la que se refiere la intervención, para evitar la práctica tan extendida de hablar sin haber leído el texto. 
g) La persona que dinamiza la tertulia modera, da el turno de palabra y hace que todos participen y comenten, al menos un párrafo, buscando una participación lo más igualitaria posible y evitando que alguien monopolice todo el tiempo.

h) La sesión se inicia planteando de forma global las siguientes preguntas: ¿Habéis traído todo el libro? ¿Habéis leído el trozo que tocaba para hoy? ¿Os ha costado mucho leerlo? ¿Os ha gustado?, ....

i) El moderador anima a que se lea despacio y lo mejor posible para que las personas con dificultades en la lectura puedan entender lo que se está leyendo.

j) La persona que tiene el turno de palabra, indica en que página está su frase o párrafo (el moderador debe comprobar que todos los participantes hayan encontrado la página antes de la lectura del párrafo), lo lee y comenta por qué le ha gustado o llamado la atención. Cuando ha terminado su intervención, si alguien quiere decir algo sobre ese párrafo, puede hacerlo pidiendo el turno de palabra. No se trata de debatir las opiniones, sino que las personas las expresen argumentándolas y escuchen las de los demás.

k) En caso de que se inicie alguna pequeña discusión, el moderador recuerda que no hay que ponerse de acuerdo, simplemente se expresa su punto de vista y lo argumenta. Se puede llegar a acuerdos temporales, siempre abiertos a nuevas reflexiones.

I) Si se observa que, en el transcurso de la tertulia, el diálogo entre los participantes entra en cuestiones personales o en temas ajenos al desarrollo de la tertulia, el moderador debe retomar la sesión.

m) La puntualidad favorece el buen funcionamiento del debate.

n) Se puede leer las páginas que se desee del libro; sin embargo, solamente se puede comentar sobre la parte acordada en cada sesión.

o) A los participantes, se les entregan por escrito las oportunas instrucciones, adaptadas a su nivel académico.

El significado, se crea a partir de las interacciones sobre el texto, al hacer el diálogo con los demás en la tertulia. Se ponen más miradas al texto y se encuentra lo que uno sólo no localiza, profundizando así en su interpretación. Al compartir las instrucciones se expresan las propias ideas, pensamientos, opiniones, emociones, ideas y vivencias. Se aprende a escuchar, respetar el turno y ordenar las propias ideas para exponerlas a los demás.

Si a estas actuaciones se articula el trabajo con obras clásicas de la literatura universal, se refuerza el trabajo realizado, ya que aportan conocimiento, optimizan el vocabulario, se obtiene comprensión de la situación histórica y mejor calidad de la literatura, comprenden y reflexionan sobre lo acontecido en el mundo y los grandes temas que preocupan a la humanidad, independientemente de la cultura o la época.

Algunas de las obras clásicas de literatura universal que se trabajan en las aulas de Educación Primaria y Secundaria las podemos ver en la Tabla 1. 
Tabla 1.

Selección de obras clásicas de la literatura universal que se trabajan en tertulias dialógicas literarias en los centros educativos.

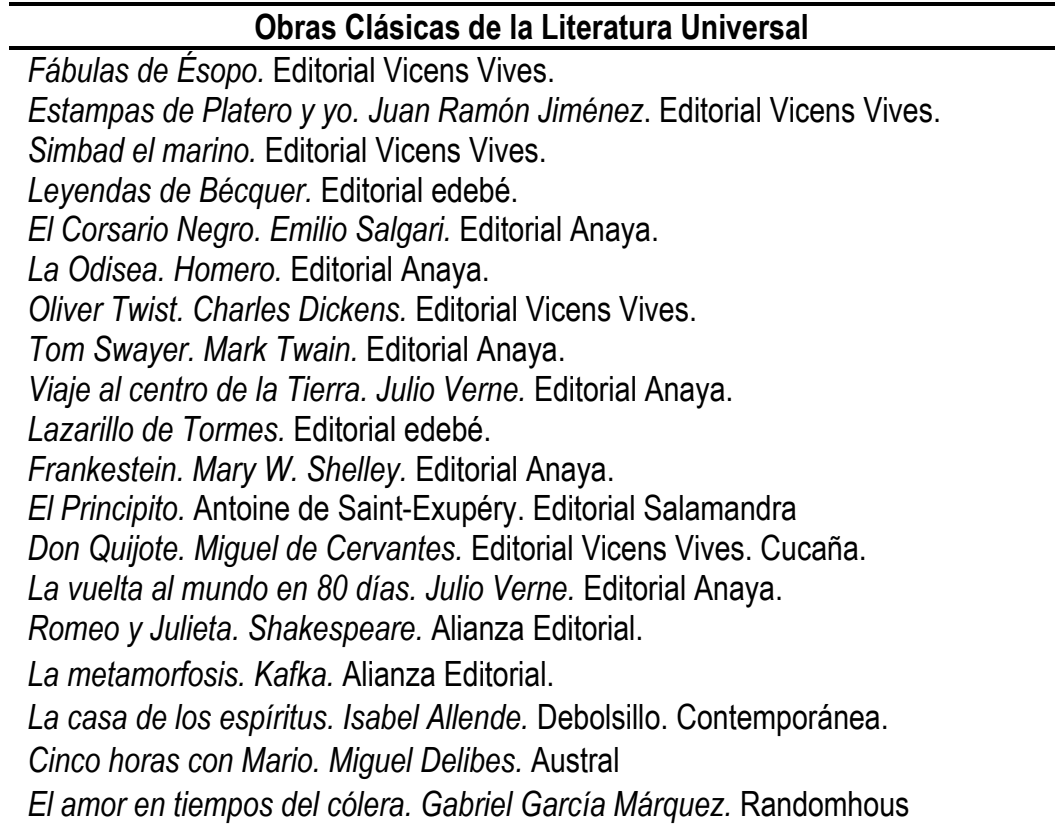

Nota: Tabla de elaboración propia.

\section{3.-Método.}

\section{1.- Diseño.}

Esta investigación cualitativa responde al enfoque comunicativo crítico (Gómez, Latorre, Sánchez, \& Flecha, 2006). Dicha metodología no solamente busca la descripción y/o interpretación de la realidad, sino que pretende provocar la transformación de esa realidad. La metodología comunicativa crítica está basada en el diálogo igualitario entre la comunidad científica y las personas cuya realidad sea objeto de investigación, de manera que la propia investigación es el resultado de una pluralidad de voces (Touraine, Wieviorka, \& Flecha, 2004).

En nuestra investigación, la comunidad científica se formalizó mediante los grupos de discusión comunicativos de alumnado y miembros de la comunidad educativa, configurándose en un grupo natural que pretende elaborar una interpretación colectiva de la realidad, a través de la comunicación entre iguales. Está formada por personas que tienen algún nexo en común como, en nuestro caso, participar en una comunidad de aprendizaje, y facilitan la existencia de este espacio de diálogo entre iguales que necesita el grupo de discusión para que la comunicación no quede 
sometida a la imposición de unas opiniones sobre otras. Junto a estos grupos, también nos ayudamos de un relato comunicativo de vida cotidiana, llevado a cabo por la Jefa de Estudios del centro, mediante un proceso comunicativo de entendimiento y reflexión en el que reflexionó y realizó interpretaciones sobre su vida y aportó su bagaje científico a la reflexión de comunidades de aprendizaje. Por todo ello, la investigación se enriquece gracias a las interpretaciones y experiencias de las "personas protagonistas" de la investigación. Además, con el fin de completar los resultados de la investigación cualitativa, también se utiliza una metodología cuantitativa para reflexionar sobre los resultados obtenidos en las pruebas de evaluación realizadas externamente por la Agencia Andaluza de Evaluación Educativa. Consejería de Educación de Andalucía (AGAEVE, 2017). Los métodos y técnicas de recogida de datos que se utilizan, así como los participantes del estudio, se muestran en la Tabla 2.

Tabla 2.

Técnicas, códigos y participantes del estudio

\begin{tabular}{ccc} 
Técnica & Código & Participantes \\
\hline $\begin{array}{c}\text { Grupos de discusión } \\
\text { comunicativos }\end{array}$ & GDPV & $\begin{array}{c}\text { Tutores/as de } 2^{\circ}, 3^{\circ} \text { y } 5^{\circ} \\
\text { EP, voluntaria miembro de } \\
\text { Secretariado Gitano, } \\
\text { madre voluntaria, la } \\
\text { maestra de pedagogía } \\
\text { terapéutica del centro y la } \\
\text { Jefa de Estudios. }\end{array}$ \\
\cline { 2 - 3 } & & $\begin{array}{c}\text { Diez alumnos y alumnas } \\
\text { de } 6^{\circ} \text { de Educación } \\
\text { Primaria }\end{array}$ \\
\hline $\begin{array}{c}\text { Relato comunicativo de } \\
\text { vida cotidiana }\end{array}$ & GDA & Jefa de Estudios \\
\hline Nota: Tabla de elaboración propia. & RCVC &
\end{tabular}

Los datos obtenidos de dichos colectivos a través de estas técnicas, cumplen con la confidencialidad de los mismos, siguiendo los protocolos establecidos, así como el consentimiento de la publicación de sus aportaciones e imágenes, siempre respetando el anonimato de todos los agentes que han participado en esta investigación. Lógicamente, dado que el derecho a la propia imagen está reconocido en el Art. 18 de la Constitución y regulado por la Ley 1/1982, de 5 de mayo, sobre el derecho al honor, a la intimidad personal y familiar y a la propia imagen y el Reglamento (UE) 2016/679 del Parlamento Europeo y del Consejo, de 27 de abril de 1016, relativo a la protección de las personas físicas en lo que respecta al tratamiento de datos personales y a la libre circulación de estos datos, los investigadores han solicitado -cuando son menores de edad- a los padres o tutores legales las pertinentes autorizaciones para poder utilizar las imágenes en las que aparecen individualmente 0 en grupo en las publicaciones de la investigación. 


\section{2.- Participantes y aplicación del instrumento.}

El presente trabajo expone el proceso del proyecto de Comunidades de Aprendizaje, desarrollado desde el curso 2010/11 hasta el curso 2015/16, en el C.E.I.P. Santa Teresa Doctora de Linares (Jaén, España), y tiene como objetivo general analizar los cambios producidos en la mejora de los rendimientos académicos, especialmente los resultados de la competencia en comunicación lingüística.

Se ha seleccionado este centro por las características peculiares que le rodean, ya que está en un barrio marginal y, el $80 \%$ del alumnado, es de etnia gitana. En consonancia con el interés de la investigación y con la perspectiva metodológica adoptada, la elección del C.E.I.P. Santa Teresa Doctora, como caso único de estudio, viene determinada por los siguientes criterios:

1) El centro trabaja el proyecto Comunidades de Aprendizaje desde 2011, y fue aprobado en el curso 2012/13.

2) En el curso 2016/17, el centro ya tiene consolidado el proyecto de Comunidades de Aprendizaje.

3) El centro se encuentra en un contexto de bajo nivel socioeconómico y con una alta presencia de población de etnia gitana.

4) El centro es pionero en Jaén y Andalucía en abordar su transformación en Comunidades de Aprendizaje.

EI C.E.I.P. Santa Teresa Doctora es de titularidad pública y está configurado por 9 unidades (3 de Educación Infantil y 6 de Educación Primaria). Su alumnado pertenece a barriadas que están consideradas como las más pobres de la ciudad. Las familias suelen estar desestructuradas y con padres en la cárcel, drogodependientes, 0 de abandono de hecho. La mayoría de ellos, están parados 0 son pensionistas, y el resto se dedica a la venta ambulante 0 vive de la recogida de chatarra, de ocupaciones de temporada, etc. Predominan las familias con un nivel cultural bajo con analfabetos funcionales.

El $80 \%$ de su alumnado es de etnia gitana y presenta fuerte déficit en las materias instrumentales; por tanto, los resultados escolares ofrecen un alto índice de fracaso escolar, especialmente en la competencia lingüística y matemática.

En el contexto en el que se circunscribe el C.E.I.P. Santa Teresa Doctora se considera que el proyecto de Comunidades de Aprendizaje facilita la transformación el centro educativo y, actuaciones educativas de éxito como las tertulias dialógicas literarias, hacen que mejore la calidad de la enseñanza y los resultados académicos en la competencia lingüística, entre otras. Efectivamente, como se ha indicado, las Comunidades de Aprendizaje son centros inclusivos comprometidos en desarrollar y potenciar prácticas y principios pedagógicos que combatan el fracaso escolar y la marginación social, donde toda la comunidad educativa está comprometida con el proyecto. Por ello, como objetivo específico se pretende conocer la práctica de tertulias dialógicas literarias en las Comunidades de Aprendizaje, estableciendo como centro educativo de referencia el C.E.I.P. Santa Teresa Doctora. Consecuentemente, 
se especifica la viabilidad y los resultados que está produciendo esta actuación educativa de éxito, centrándonos en la mejora de los resultados académicos en la competencia en comunicación lingüística, atendiendo también a aspectos como velocidad lectora y porcentaje de errores en lectura.

Las tertulias dialógicas literarias, se manifiestan en todas las aulas del C.E.I.P. Santa Teresa Doctora de Linares, desde el curso 2012/13. Se realizan una vez a la semana, en cada una de las aulas del centro siguiendo unas instrucciones. El análisis de la información que se obtiene, a través de las técnicas de grupos de discusión comunicativos y el relato comunicativo de vida cotidiana, se elabora de manera cualitativa, remarcando en los aspectos que nos interesan para llegar al objetivo del estudio. Asimismo, analizaremos de manera cuantitativa los resultados obtenidos desde el curso 2010/11 hasta el curso 2015/16, a través del análisis de las evaluaciones de diagnóstico realizadas al alumnado del centro educativo por la Agencia Andaluza de Evaluación Educativa de la Consejería de Educación de Andalucía (AGAEVE, 2017).

\section{INSTRUCCIONES LA TERTULIA DIALÓGICA}

Lee el texto y si algún párrafo/s te llama/n la atención, subráyalo/s y, si quieres, o crees que es necesario para recordarlo, escribe en un papel (como si fuera una chuleta) por qué lo has elegido, es decir, las razones que has tenido para marcarlo. Es recomendable marcar más de un párrafo.

En la Tertulia, tendrás oportunidad de leer en voz alta el/los párrafo/s (según el tiempo de que dispongamos). Antes de hacerlo indicarás en qué página están y dónde lo podemos localizar (arriba, en medio, abajo...). Después de leerlo nos comentarás por qué lo has elegido, qué es lo que te sugirió o qué es lo que llamó la atención (porque te gustó o porque no te gustó, porque te recordó algo o a alguien, porque estás de acuerdo 0 en desacuerdo con lo que dice, porque es bonito...) lo que no vale decir es: porque sí o porque no; ya que lo que ha de primar son los argumentos. Como verás, es una especie de comentario, no de un comentario literario, sino de un comentario personal. Luego, si algún/a contertulio/a quiere opinar sobre tu comentario o, simplemente, comentar el párrafo que has leído, es el momento adecuado. $Y$ así iremos consumiendo el tiempo que dediquemos a la práctica.

Cuadro 1. Instrucciones para dar a los participantes de la tertulia antes de realizarla en el aula. Nota: Elaboración propia.

\section{4.-Resultados y discusión.}

Una vez recopilada y transcrita toda la información, fuimos subrayando la información relevante para nuestro objeto de estudio y al margen anotábamos la categoría 0 dimensiones a las que pertenecía cada cita, añadiendo el código para facilitarnos luego la inclusión dentro del informe de dichos datos y la interpretación que este investigador hacía de dicha cita o información seleccionada. Posteriormente agrupamos cada una de las citas seleccionadas dentro de su dimensión y categoría correspondiente: Mejora educativa (rendimiento académico, clima de aula, mejora del aprendizaje y/o motivación) o inclusión educativa (cooperación entre igual, papel de 
la comunidad e integración/inclusión educativa de alumnado con necesidades educativas especiales).

Una vez agrupadas en su categoría, con su código identificativo y con la interpretación individual realizada por este investigador, llegó el momento de presentar a los participantes y otros expertos nuestras descripciones e interpretaciones para que pudieran aportar otro análisis o interpretación diferente, dudas o tratar de completar alguna información incompleta o sesgada para, finalmente, llegar a un consenso de cada interpretación.

Era ahora el momento de comenzar a relatar nuestro informe de investigación y de realizar un análisis de los resultados obtenidos que muestran cómo se percibe la experiencia por parte del alumnado, profesorado y otros participantes en las tertulias dialógicas literarias. De ellos se deduce que, la puesta en práctica de dichas tertulias fue diseñada, implementada y evaluada con éxito. A título indicativo se aporta la apreciación realizada por MPT del GDPV:

Una de las metas primordiales de las Comunidades de Aprendizaje es la obtención de buenos resultados académicos por parte de todo el alumnado, ya que los buenos resultados académicos van acompañados, generalmente, de la superación de las desigualdades y la inclusión educativa. Por ello, con las tertulias se ha acercado a los niños la literatura, música, arte... cosa que, si no fuera de esta manera, no hubiera llegado hasta ellos con tanta intensidad (MPT).

En similar sentido se manifiesta M1 del GDPV:

Con las tertulias hemos aproximado a los niños a la literatura (...). Pero, lo que más me gusta de todo, es el hecho de que los padres vengan y vean a sus hijos dentro de las aulas y que participen y muestren interés. Hemos conseguido que los padres colaboren con nosotros y vean lo importante que es la educación de sus hijos. Los niños están deseando que lleguen a la clase y los buscan (...). Otro aspecto que no tienen otros centros es el nivel de ayuda que se da entre el alumnado dentro del aula, especialmente, a través de los grupos interactivos (M1 del GDPV).

Se ha evidenciado que, entre las actuaciones educativas de éxito más demandadas por el alumnado y que más gustan al profesorado, y a la comunidad educativa, se sitúan las tertulias dialógicas literarias, ya que aprenden juntos leyendo e interpretando un libro de la literatura clásica universal en la que suelen participar familiares que aportan nuevas perspectivas al aula, como indica M2 del GDPV:

Las Actuaciones Educativas de Éxito son todas muy positivas, pero yo destacaría las tertulias, sobre todo, porque trabajan partes del aprendizaje fundamentales como la expresión oral, comprensión lectora... y transmitir y compartir sentimientos, emociones y valores que muchas veces quedan un 
poco en el olvido y creo que es base fundamental de la educación (M2 del GDPV).

Sobre los efectos en el rendimiento académico del alumnado asociados a la organización inclusiva del aula se puede indicar que, cuando se utiliza el aprendizaje dialógico a través de actuaciones como las tertulias dialógicas literarias, el rendimiento académico mejora, tanto en el alumnado que obtiene buenos resultados, como en el que tiene un menor nivel de aprendizaje, ya que éste último se beneficia y enriquece de todas las aportaciones que se hacen en el grupo durante la tertulia. En esta línea, se destacan las manifestaciones de T del GDA:

A mí me encantan las tertulias dialógicas literarias porque hablamos de temas que nos ayudan y todo ello a través de un libro. Además, cuando interviene la maestra o los padres, nos sentimos como más cercanos a ellos, más a gusto en la clase (T del GDA).

Igualmente, el alumnado que menos habla o que presenta dificultades en el aprendizaje, desarrolla una mayor autoestima en clases integradas y que trabajan mediante tertulias dialógicas literarias, proporcionando nuevas oportunidades de aprendizaje para todos, a partir de la visión intersubjetiva del texto que se está leyendo, cambiando incluso la manera de ver la vida en algunos participantes, como expresa RCVC:

Quiero centrarme en las tertulias dialógicas literarias, personalmente una de las Actuaciones Educativas de Éxito que más me gustan y donde vemos que el alumnado va mejorando en aspectos de lectura, expresión oral... Eran niños, no sólo que hablaban mal, es que no hablaban nada. Entonces, a través de las lecturas compartidas en cualquier curso, cualquier niño es capaz de hablar libremente. Las niñas gitanas en cualquier tertulia hablan y ven la vida de forma diferente a la que la veían antes, dándole más valor a la educación (RCVC).

Analizados los resultados de las evaluaciones externas realizadas por Agencia Andaluza de Evaluación Educativa. Consejería de Educación de Andalucía (AGAEVE, 2017), en la Tabla 3 se expresan los resultados positivos que ha obtenido el C.E.I.P. Santa Teresa Doctora, lográndose una puntuación durante el curso 2015/16 superior a los centros de la zona y de la media andaluza. Lo que permite confirmar que, la composición cultural del alumnado no es siempre lo que influye en los resultados académicos, sino que también influye la aplicación de actuaciones educativas de éxito.

Tabla 3.

Resultados Prueba Escala (2011/12 al 2015/16)

\section{Competencia en Comunicación Lingüística}


Revista Internacional de Apoyo a la Inclusión, Logopedia, Sociedad y Multiculturalidad. Volumen 5, Número 3, Diciembre 2019, ISSN: 2387-0907. DOI: https://doi.org/10.17561/riai.v5.n3

\begin{tabular}{|c|c|c|c|c|c|}
\hline (Máxima puntuación: 6 puntos) & $11 / 12$ & $12 / 13$ & $13 / 14$ & $14 / 15$ & $\begin{array}{c}15 / 1 \\
6\end{array}$ \\
\hline Comprensión lectora & 3.0 & 4.2 & 5.0 & 5.6 & 5.8 \\
\hline Expresión escrita & 2.0 & 2.4 & 4.9 & 3.2 & 4.8 \\
\hline
\end{tabular}

Fuente: Agencia Andaluza de Evaluación Educativa. Consejería de Educación de Andalucía.

Asimismo, mejoran otros aspectos, no menos importantes, de esta competencia en comunicación lingüística, como la velocidad lectora (Figura 2), y disminución del porcentaje de errores durante la lectura (Figura 3).

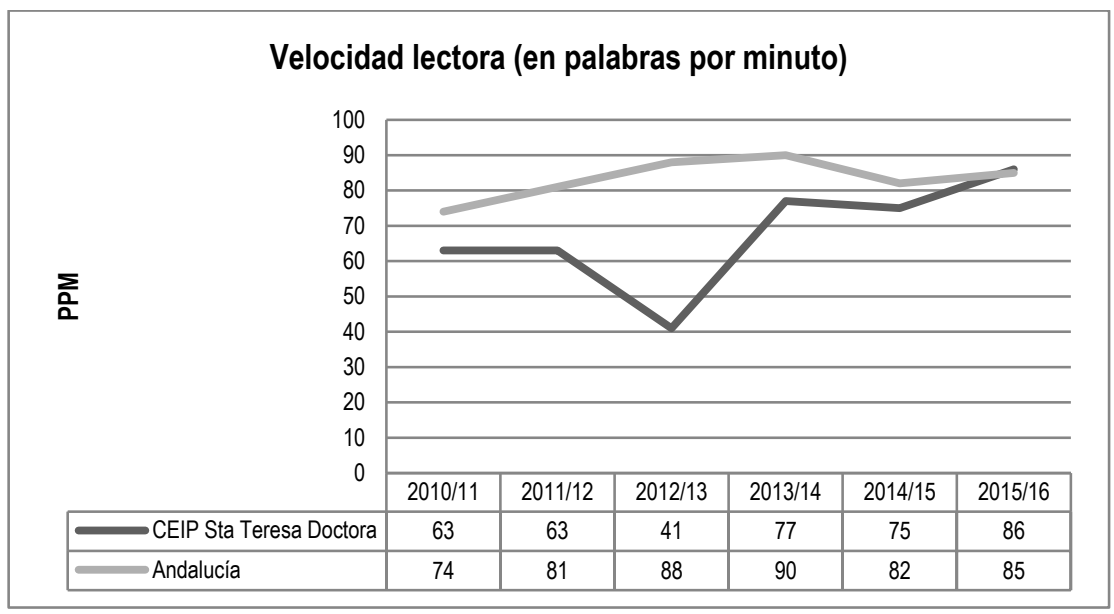

Figura 2. Resultados Prueba Diagnóstico sobre Velocidad lectora en palabras por minuto (2010/11 al 2015/16). Fuente: Agencia Andaluza de Evaluación Educativa. Consejería de Educación de Andalucía (AGAEVE, 2017).

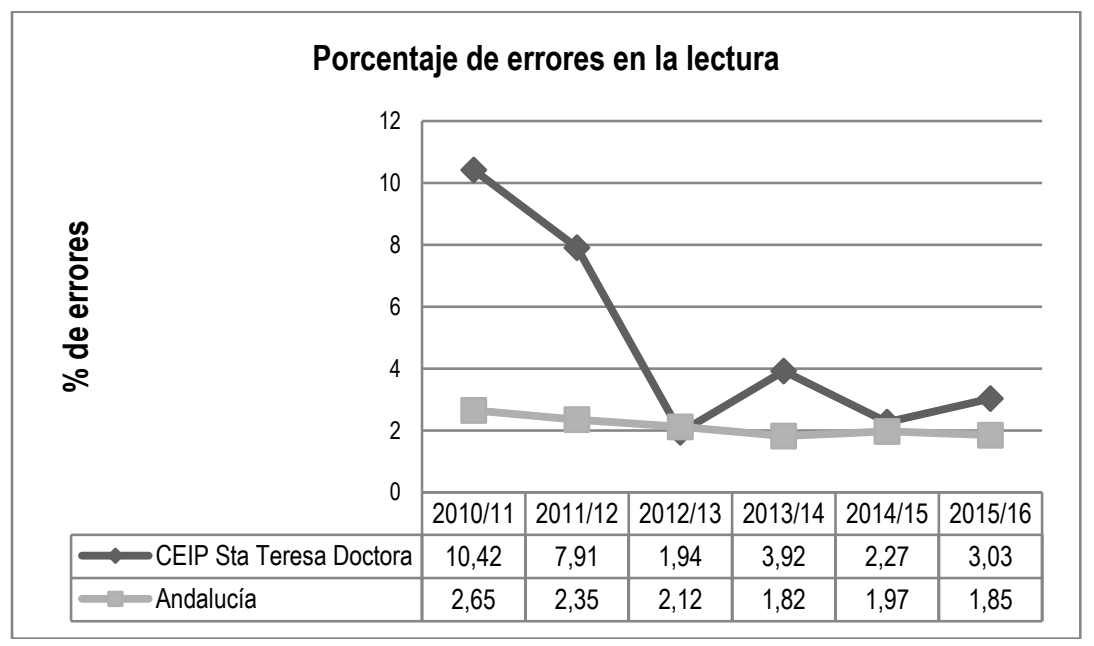


Figura 3. Resultados Prueba Diagnóstico sobre Porcentaje de errores en la lectura (2010/11 al 2015/16). Fuente: Agencia Andaluza de Evaluación Educativa. Consejería de Educación de Andalucía (AGAEVE, 2017).

\section{5.-Conclusiones.}

Se ha comprobado que, con relación a la competencia en comunicación lingüística, los resultados de la investigación nos permiten observar que, Comunidades de Aprendizaje mejora el rendimiento académico del alumnado, en pruebas internas y externas en dicha competencia. En esta mejora influyen, en gran medida, la organización del aula y la práctica de las tertulias dialógicas literarias de manera sistemática.

Es importante destacar que, la realización de tertulias literarias dialógicas en el centro educativo no solamente constituye una oportunidad de acercarse a la literatura clásica, sino que, al fomentar el diálogo e intercambio de interpretaciones derivadas de la lectura de la obra, se construye un conocimiento compartido a partir del texto leído, se refuerza una lectura crítica y la comprensión lectora, y se optimizan habilidades cognitivas en relación con la lectura.

En consecuencia, los resultados obtenidos animan a los equipos directivos y a todos los docentes, familiares y voluntariado para continuar con esta línea de trabajo. La viabilidad de este proyecto es, sin duda, un hecho plausible. La propuesta que se ha presentado de tertulias dialógicas literarias ha tenido un impacto positivo en las aulas, pues se trata de una iniciativa innovadora, en la que se hace uso de las habilidades expertas hacia la lectura y la literatura que tiene el alumnado para transmitirlas al grupo-clase, enriquecido aún más con la presencia de familiares y voluntariado. En definitiva, como indica Soler (2003) son pocas las veces que se aprovecha en los centros educativos el potencial de las relaciones intergeneracionales. Por tanto, es preciso insistir, como subraya Azorín (2016), en la importancia de abrir fronteras y eliminar barreras en la comunidad educativa sirviéndonos de estrategias como las tertulias dialógicas literarias para construir puentes que permitan mejorar la inclusión y la convivencia en la escuela, así como fomentar el gusto por la lectura.

Se coincide con otras investigaciones sobre la necesidad de una intervención integrada y comunitaria para la superación de la pobreza y la exclusión socioeducativa, que permita abordar las dos circunstancias que más incrementan la vulnerabilidad ante la pobreza: la falta de formación académica y la precariedad e inactividad laboral (Girbés, Macías, \& Álvarez, 2015).

De la misma forma, como especifica Santos (2015) en su estudio sobre la superación de la pobreza en Brasil, para asegurar la superación de la desigualdad de manera sostenible y a largo plazo, se revela que la educación es una variable clave para la transformación de estos barrios marginales. Todo ello ha sido también evidenciado 
en la experiencia desarrollada en el colegio La Paz de Albacete (García-López, Martínez-Soriano, García-Villafruela, \& Ruiz-Escribano, 2017).

Motivadamente, junto a las mejoras que hemos expuesto anteriormente, en el C.E.I.P. Santa Teresa Doctora de Linares (Jaén), se han reducido las tasas de abandono escolar y/o absentismo, ha mejorado la convivencia a nivel de centro y de aula, los resultados académicos, y coexiste una verdadera inclusión educativa. Se puede demostrar que existen prácticas, en este centro educativo, que pueden transferirse a la escuela tradicional y que repercutirían positivamente en el rendimiento académico y en la interacción social del alumnado, así como a todos los centros que ya están transformados en Comunidad de Aprendizaje, como:

a) Trabajo en equipo (implica desarrollar unos hábitos de convivencia, comunicación, decisión, responsabilidad, valoración...)

b) Diálogo igualitario.

c) Inclusión de las familias (la comunicación entre la familia y el profesor en un diálogo entre iguales conducente a promover y facilitar el aprendizaje del alumnado dando el soporte necesario a las familias, es un elemento clave para mejorar los problemas que subyacen a lo largo de la vida escolar)

d) Enseñanza compartida entre el equipo docente.

e) Apoyo dentro del aula.

f) Metodologías flexibles y activas como grupos interactivos, tertulias dialógicas...

Los resultados de esta investigación coinciden con otras, como las realizadas por Foncillas y Laorden (2014), que muestran cómo el aprendizaje construido entre todos desde el diálogo, la reflexión y la crítica es más satisfactorio y conecta con la realidad social que están viviendo y el entorno más próximo.

Igualmente, como indican Cantero y Pantoja (2016), conviene subrayar la importancia de la implicación en la gestión del equipo directivo en la motivación y empuje del proyecto en el centro, que asegure la implicación del profesorado y el impulso de la participación de la familia y el voluntariado. Motivadamente, partiendo de modelos con prácticas exitosas, como las Comunidades de Aprendizaje, identificado otras actuaciones de éxito, fuera del ámbito educativo, que permiten la superación de la exclusión social en otros ámbitos sociales como el acceso a la vivienda, la salud o el empleo, permite abordar la situación de la exclusión desde un enfoque integrado, vinculando las políticas educativas con las sociales. De esta manera, como resalta Santos (2015), se crean condiciones para la superación de la exclusión desde estos ámbitos sociales.

En próximos trabajos se profundizará en la formación docente basada en la colaboración, la democracia, la equidad, el diálogo y la práctica reflexiva, para aprender a generar conocimiento de sus propias prácticas y responder a los principios de solidaridad, tolerancia, y justicia social. 


\section{6.-Referencias.}

AGAEVE (2017). Resultados de la Prueba de Evaluación Escala 2015/16 del C.E.I.P. Santa Teresa Doctora de Linares (Jaén). Sevilla: Agencia Andaluza de Evaluación Educativa. Consejería de Educación de Andalucía.

Aubert, A., Flecha, A., García, C., Flecha, R., Racionero, S. (2008). Aprendizaje dialógico en la Sociedad de la Información. Barcelona: Hipatia.

Cantero, N., Pantoja, A. (2016). La transformación de centros educativos en Comunidades de Aprendizaje ( $\mathrm{CdA})$ en la provincia de Jaén. Profesorado. Revista de Currículum y Formación de Profesorado, 20. Recuperado de http://www.redalyc.org/articulo.oa?id=56749100021

Girbés, S., Macías, F., Álvarez, P. (2015). De la Escuela Gueto a una Comunidad de Aprendizaje: Un Estudio de Caso sobre la Superación de la Pobreza a través de una Educación de Éxito. RIMCIS. International and Multidisciplinary Journal of Social Sciences, 4(1), 88-116. doi: http://dx.doi.org/10.17583/rimcis.2015.1470

Gómez, J., Latorre, A., Sánchez, M., Flecha R. (2006). Metodología comunicativa crítica. Barcelona: El Roure.

INCLUD-ED (2011). Actuaciones de éxito en las escuelas europeas. Madrid: Ministerio de Educación, Cultura y Deporte. Subdirección General de Documentación y Publicaciones.

Levin, H.M. et al. (1995). Volver a pensar la educación. Vol II: Prácticas y discursos educativos. En Congreso Internacional de Didáctica. La Coruña: Fundación Paideia.

Loza, M. (2004). Tertulias Literarias. Cuadernos de Pedagogía, 34 (1), 66-69.

MECD (2013). Objetivos educativos europeos y españoles. Estrategia educación y formación 2020. Madrid: MECD. Secretaría de Estado de Educación, Formación Profesional y Universidades. Conferencia de educación.

Valls, R., Kyriakides, L. (2013). The power of Interactive Groups: how diversity of adults volunteering in classroom groups can promote inclusion and success for children of vulnerable minority ethnic populations. Cambridge Journal of Education, 43 (1), 17-33. 